\title{
¿COOPERACIÓN O AYUDA? ANÁLISIS COMPARADO DE LA POLÍTICA DE COOPERACIÓN INTERNACIONAL AL DESARROLLO ESPAÑOLA EN EDUCACIÓN EN AMÉRICA LATINA
}

\author{
Ma Jesús Martínez Usarralde \\ Universidad de Valencia
}

\begin{abstract}
RESUMEN: El objetivo de este artículo es el de escrutar cuál es la identidad de la política de cooperación al desarrollo española, a través de la Ayuda Oficial al Desarrollo en materia educativa sobre seis países de América Latina. Avalada por los datos y tendencias extraídas de este análisis comparado, se pretende demostrar cómo la política de cooperación al desarrollo en educación española en estos países no concentra su atención en educación básica, en detrimento de otros niveles educativos, al tiempo que se echan en falta otros aspectos, como la atención al cumplimiento de los derechos de la infancia.
\end{abstract}

ABSTRACT: This article pursues the aim to scrutinize which is the identity of the Spanish policy of Cooperation for Development, trough the Official Aid to Development and the contribution that it takes on education in seven countries of Latin America. Supported by the information and trends extracted from this compared analysis, it tries to demonstrate how the Spanish policy of cooperation in education does not pay attention enough on basic education, compared to other educational levels. At the same time, other aspects are missed, as the attention to the fulfilment of the rights of the childhood.

PALABRAS CLAVE: Cooperación internacional para el desarrollo, Ayuda Oficial al Desarrollo, Educación Básica.

KEYWORDS: International Cooperation for Development, Official Aid for Development, Basic Education.

Recibido: $14 / 07 / 2010$

Aceptado: 15/10/2010

¿Se quiere denominar "cooperación" cuando en realidad se está aplicando una mera "ayuda" al desarrollo? El presente artículo tratará de contestar a esta pregunta, mientras persigue el objetivo de escrutar cuál es la idiosincrasia de la política de cooperación al desarrollo española, a través de la AOD (Ayuda Oficial al Desarrollo) en materia de la aportación que realiza sobre educación en diferentes países de América Latina: Brasil, Argentina, Perú, Colombia, Uruguay y Paraguay. Se partirá de la hipó- 
tesis de que la AOD española en materia educativa no es, hoy por hoy, excesivamente sensible a los requerimientos y demandas socioeducativas básicas que se hacen desde los países escogidos, pertenecientes todos ellos a la región latinoamericana.

Para llevar a cabo este cometido, se revisará en primer lugar cuáles son las señas de identidad de la política española de cooperación al desarrollo, analizando el estado de la cuestión al respecto y destacando las luces y sombras tanto de la retórica política como de la realidad concerniente a la AOD en el tema que nos ocupa. En segundo lugar, se examinarán las prioridades escogidas por la DGPOLDE (Dirección General de Planificación y Evaluación de Políticas de Desarrollo) para trabajar el vector educativo desde una perspectiva macro y en los países escogidos para el estudio de América Latina como ejemplo de política más micro. A continuación, en tercero, es mi intención sumergirme en los países objeto de estudio haciendo una radiografía educativa a partir de los últimos datos arrojados por el documento emitido por UNESCO EFA 'Superar la desigualdad: por qué es importante la gobernanza. Informe de seguimiento de la EPT en el Mundo 2009', a fin de detectar cuáles son sus principales demandas. Finalmente, en la última parte de este artículo pretendo contrastar cuáles son las apuestas de la AOD educativa de la región frente a todo el espectro analizado anteriormente, de lo que se extraerán las pertinentes conclusiones remitiéndonos para ello a la hipótesis inicial.

Antes de comenzar con el análisis propiamente dicho, me gustaría incidir en dos aspectos que condicionan el contenido de las siguientes páginas: en primer lugar, la elección de las unidades de comparación. He escogido de manera no casual Argentina, Colombia, Brasil, Perú, Uruguay y Paraguay. Además de la cercanía espacial, he querido medir el pulso de estos países de América Latina que se encuentran especialmente desarrollados desde el punto de vista económico y social', en vez de optar por analizar otra serie de países cuyos datos hubieran sido, sin duda, divergentes e incluso más representativos respecto a esta elección: Ecuador, Venezuela, Nicaragua, Honduras, etc. No hemos de perder de vista, de hecho, que, de los países escogidos, varios de ellos se consideren prioritarios por la $\mathrm{AOD}^{2}$, a pesar de que su situación global sea, como he señalado, sensiblemente mejor que otros países de la misma región. De esta realidad cabe hacer, por tanto, una primera interpretación de cuáles son las prioridades y objetivos de un instrumento distributivo como es, en efecto, la Ayuda Oficial al Desarrollo. En segundo lugar, y en lo que respecta al análisis de datos procedentes de los informes EFA (también conocidas por sus siglas en castellano, 'Educación Para Todos'-EPT, emitidos desde UNESCO), condicionado además por la extensión limitada del presente trabajo, me he centrado en leer datos procedentes del ámbito educa-

1. Aunque, obviamente, haya que hacer matices entre ellos, llegando a establecer hasta dos grupos: mientras Brasil, Uruguay y Argentina son considerados por su nivel de renta, según el CAD (Comité de Ayuda al Desarrollo de la OCDE), como países de ingreso mediano-alto (entre 3031\$ y $9360 \$$ de PIB en 1998), Colombia, Paraguay y Perú son concebidos por el mismo como países de ingreso mediano-bajo (entre $761 \$$ y $3030 \$$ de PIB en 1998).

2. Así lo indica el Plan Director 2009-2012, que clasifica a los países objeto de Ayuda en A, B y C. De los países aquí analizados, al grupo A (denominados 'de asociación amplia', corresponden Paraguay y Perú; al grupo B ('asociación focalizada'), Colombia y finalmente al grupo C ('asociación para la consolidación de logros para el desarrollo'), Argentina, Brasil y Uruguay. 
tivo desde un punto de vista global, favorecidos éstos con el análisis del indicador IDE (Indicador de Desarrollo Educativo) y cifras correspondientes a educación primaria, aun sabiendo que el gran reto que detentan buena parte de los países en vías de desarrollo se concentra precisamente en el grado de educación secundaria y la permanencia en el mismo del alumnado masculino y femenino. De nuevo, deseo partir de la importancia concedida a la premisa de la 'educación básica' como derecho y como factor estratégico de desarrollo, promovida sin descanso desde UNESCO y legitimada desde otros organismos internacionales, y para ello me parece sustancial el análisis a este nivel educativo, al que uno la educación pre-primaria, con el fin de conocer su estado en los países escogidos 3 . Junto a éstos, se ofrecerán cuadros que, creo, completan la radiografía socioeducativa que pretendo proyectar sobre estos países: datos demográficos y relativos al SIDA; PIB, pobreza y desigualdad; infancia fuera de la escuela, tasas de repetición y de egreso.

\section{LA AOD ESPAÑOLA EN ACCIÓN: LUCES Y SOMBRAS DESDE LA LITERATURA ESPECIALIZADA}

La Ayuda Oficial al Desarrollo (de aquí en adelante 'AOD') constituye el centro neurálgico de la política de cooperación al desarrollo española. Puede definirse como una parte de la cooperación internacional para el desarrollo consistente en la ayuda financiera y técnica acordada por el sector público de un país desarrollado con el objeto de promover el desarrollo de los países en vías de desarrollo. Las Naciones Unidas recomendaron a los países del Norte, en 1972, a raíz de una Conferencia sobre Comercio y Desarrollo, que éstos destinaran una cantidad equivalente al 1,1\% de su PIB (Producto Interior Bruto) ${ }^{4}$, cantidad que posteriormente se dividió entre un $0,7 \%$ que correspondería a las administraciones públicas y un 0,3 que sería responsabilidad de los propios países. Sin embargo, durante todos estos años, el nivel de cooperación sólo ha llegado al 0,35\% del PIB y a lo anterior ha de añadirse que pocos países cumplen esa recomendación. De hecho, cifras recientes señalan que la AOD cayó un 20\% en términos generales, entre 1990 y 2005 (CONGDE, 2006) y que las aportaciones a la cooperación internacional se situaron en un promedio de $0,28 \%$ del PIB de sus donantes en 2007 (Intermón Oxfam, 2008). Sólo cinco países donantes han alcanzado o superado el objetivo internacional de dedicar el 0,7\% de su PIB a la cooperación al desarrollo de países pobres. Es el caso de Dinamarca, Noruega, Suecia, Holanda y Luxemburgo, que incluso superan la cifra sugerida a nivel euro-

3. La 'educación básica' puede entenderse bajo la definición, tan sencilla como rotunda, de "aquélla que satisface las necesidades educativas elementales de todos y todas". Bajo esta premisa, "es imprescindible facilitar el empoderamiento de los grupos en riesgo reduciendo su vulnerabilidad a través de un mínimo de 11 ó 12 años de exposición sistemática a los efectos de la educación desde la primera infancia (al menos desde los 5 años), y poner a su disposición algunas vías de acceso a oportunidades educativas durante toda la vida adulta" (Vélaz de Medrano, 2005, p. 11).

4. Hoy en día, con respecto a esta cifra, la UNESCO ha hecho cálculos y concluye que haría falta un $6,5 \%$ del PIB como cantidad que habría de aceptarse si verdaderamente se quiere terminar con la distancia entre los dos mundos. 
peo. Frente a éstos, los donantes que recortaron de manera llamativa su AOD en términos reales han sido Japón y Reino Unido, con un 30\%; Francia, con un 16\% y Bélgica, Estados Unidos y Portugal, con un 10\%, respectivamente (CONGDE, 2004). En promedio, también desciende el esfuerzo global de los donantes europeos, no cumpliendo con ello el compromiso de destinar en 2010 el 0,56\% de su PIB a países en desarrollo. En este escenario, y a pesar de que el gobierno español haya declarado con firmeza su propósito de alcanzar el 0,7\% de la AOD para el 2012, se encienden luces de alarma para cumplir este compromiso, dado que en 2009 el nivel de la ayuda se mantenía en un todavía poco complaciente 0,49\%.

Para avanzar en el discurso, hay que distinguir dos tipos de AOD, si seguimos el criterio de identificar a los protagonistas de la cooperación (Alonso, 1999): la cooperación bilateral, por un lado, cuyo flujo se lleva a cabo en forma de recursos humanos calificados, material y equipo, fortalecimiento institucional, y/o flujos de capital de un país desarrollado a un país en desarrollo. La cooperación multilateral, por su parte, se articula a través de organismos transnacionales que reciben aportes de varios países desarrollados y otros países miembros. Por tanto, los fondos son entregados a estos organismos internacionales para la financiación de proyectos que gestionan ellos mismos. Estos organismos internacionales se dividen, a efectos de su estudio, en tres bloques diferenciados: Naciones Unidas (incluida FAO, UNICEF, OMS, la Cruz Roja, Ayuda al Refugiado, Ayuda en Acción, etc.); el Banco Mundial y la Unión Europea 5 .

Con respecto a esta primera clasificación, la realidad de la cooperación española actual arroja un dato determinante como clave interpretativa de la naturaleza y fines de la cooperación española: en porcentajes, 1/3 de la AOD se destina a las contribuciones para los organismos internacionales (cooperación multilateral) y los otros dos tercios se derivan a gastos sobre la cooperación bilateral ${ }^{6}$.

La AECID (Agencia Española de Cooperación Internacional y Desarrollo), institución que se creó en noviembre de 1988 como órgano ejecutor de la política espa-

5. La Unión Europea, tal y como señala el Ministerio de Asuntos Exteriores y CooperaciónMAEC (2009), constituye el principal donante mundial. Los objetivos de la política comunitaria de desarrollo se concentran en torno a la lucha contra la pobreza, la vinculación entre el comercio y la ayuda al desarrollo, la contribución a la integración de bloques regionales, a partir de la propia experiencia europea; la reforma macroeconómica y la concepción del ajuste estructural en paralelo con el énfasis en el gasto social y el apoyo al desarrollo de la capacidad institucional en los países del desarrollo. Esta enumeración, en palabras de Jordán y Antuñano (2001), no ha de ser considerada como una cláusula de salvaguardia de las conciencias occidentales, sino que forma parte del proyecto a partir del cual la Unión Europea ha comenzado un proceso de reflexión y reforma que debe culminar en un sistema distinto de ejecución de la cooperación, más rápido y eficaz. En los momentos de escribir estas líneas, España ocupa, durante los primeros seis meses del año 2010, la Presidencia de la Unión Europea, además de suponer el principio de la cuenta atrás para el cumplimiento estimado de los ODM para el 2015, con lo que nos encontramos en una coyuntura que representa un enorme reto $y$, a la vez, una gran oportunidad estratégica para la política de cooperación internacional y española.

6. Aunque aquí también quizá sea pertinente hacer un matiz, cuanto menos que significativo, a la luz de los datos de uno de los últimos informes del Plan Anual de Cooperación Internacional, que indica que "en el ejercicio 2009 se ha producido un notable aumento de la ayuda canalizada por la vía multilateral en la AOD española (...). Las aportaciones de la Unión Europea $(692,7$ 
ñola de cooperación para el desarrollo, en especial para la ayuda bilateral no reembolsable y las subvenciones a las ONGDs ${ }^{7}$, constituye el órgano de gestión de la política española de cooperación internacional para el desarrollo, tal y como lo refrenda la Ley 23/1998, de Cooperación Internacional para el Desarrollo. La propia Ley establece que la política española de cooperación al desarrollo se articula en torno a dos ejes de prioridades, que determinarán sus líneas de actuación preferente: el carácter geográfico, orientado a regiones y países que sean objeto preferente de cooperación española, y el carácter sectorial.

Es, precisamente, al primero de estos ejes al que quiero referirme para finalizar este apartado necesariamente propedéutico y avanzar en este análisis: América Latina como eje de carácter geográfico. Al segundo de ellos, el carácter sectorial y, más específicamente, el educativo, le dedicaré la siguiente sección.

Volviendo sobre el primero de ellos, la vinculación de la AOD con América Latina, merece la pena recordar cómo es esta región la que ha constituido la prioridad de la política española de cooperación durante todos estos últimos años (Intermón Oxfam, 2008): el 44\% de la ayuda española de cooperación entre el periodo de 1985 a 2002 ha correspondido a la misma. Con datos más recientes, en 2008 la región detenta un 47,5\% de los fondos de la AECID distribuibles por regiones, con un ligero descenso del 0,5\% respecto al año pasado (MAEC, 2009). Si acudimos, además, con un carácter complementario al anterior, al peso e impacto que sobre la región tiene la denominada 'cooperación descentralizada's, el interés hacia la misma aumenta: el 47\% de la AOD de entidades locales también tuvo como destino prioritario América Latina en el año 2008 (MAEC, 2009a, pp. 148-149). No puedo estar más de acuerdo con las razones que avalan, según Sánchez (2008), el análisis de la misma frente a otras regiones también susceptibles de estudio correspondientes a países en desarrollo: a los motivos ampliamente conocidos de carácter socio-histórico y de compartir un pasado y lengua comunes, se suma el hecho de que en esta región se concentran más de 200 millones de personas que viven en la pobreza, de los que un millón lo hace en la indigencia y por último porque "los

millones de euros) experimentaron un ligero incremento de apenas 15 millones de euros respecto a 2008 (...). En cuanto a contribuciones a los Organismos Multilaterales financieros, la aportación española ha aumentado con respecto al ejercicio 2008, y pasa de 322 millones a 389 millones de euros, con más del 67\% dirigido a aportaciones del Banco Mundial (...). Pero el gran salto multilateral ha venido por el lado del incremento de las aportaciones a organismos multilaterales de desarrollo y fondos dirigidos a países, sectores o vinculados a iniciativas de alcance global, en solitario o junto con otros donantes, que en el ejercicio han alcanzado la cifra de 1177,3 millones de euros (...). El principal destinatario multilateral de la ayuda española ha sido el sistema de Naciones Unidas, que ha alcanzado los 929,4 millones de euros (una cuarta parte del total de la AOD española de 2009)" (MAEC, 2010, p. 40).

7. Ésta se produce por medio de dos concursos anuales: la convocatoria ordinaria con cargo a los presupuestos del Ministerio de Asuntos Exteriores y la convocatoria extraordinaria derivada de los recursos consignados a acciones de interés social en el IRPF que se dona a través de la declaración de la renta.

8. Bajo esta denominación, esta modalidad puede definirse como la cooperación acometida desde las comunidades autónomas y, dentro de éstas, desde las entidades locales. 
cambios políticos y económicos por los que ha atravesado en las últimas décadas, unido a la importancia estratégica que para España tiene esta región, la convierte en un área sensible a los cambios de orientación de la política de cooperación española" (p. 111) . Con datos recientes del Seguimiento del PACI (Plan Anual de Cooperación Internacional) para el periodo 2009-2012 se reconoce que la AOD bilateral bruta española continua su evolución ascendente y pasa de un $36 \%$ en 2005 a un 41,2\% en 2006 y a un 46,5\% en 2007 (MAEC, 2009, p. 33), siendo Perú y Colombia los dos países receptores principales ${ }^{10}$.

\section{AOD Y EDUCACIÓN: ALGUNOS PUNTOS DEL DEBATE}

En cuanto al segundo de los criterios que esgrimí líneas arriba, el sectorial, deseo centrarme en concreto en la atención que presta la AOD al ámbito de la educación, refrendado desde documentos tan significativos como el Plan Director de Cooperación española 2009-2012, que aporta el marco político que justifica la ayuda en este ámbito y desde el que se señala que "la cooperación española considera la educación como un derecho humano, además de cómo la palanca adecuada para fortalecer la equidad y la cohesión social en el marco de la lucha contra la pobreza" (PACl, 2009: 27-28), así como el último de los informes publicados desde EPT (Educación para Todos-UNESCO) (2009), al que me referiré a lo largo del texto. Para ello hemos de recurrir primeramente a lo que las cifras ofrecen a la mirada atenta:

Tabla 1. Evolución de la $A O D$ bilateral bruta en educación de la $A E C I D$

\begin{tabular}{|l|c|c|c|c|c|c|}
\hline & $\mathbf{2 0 0 5}$ & $\mathbf{2 0 0 6}$ & $\mathbf{2 0 0 7}$ & $\mathbf{2 0 0 8}$ & $\mathbf{\%} \mathbf{2 0 0 8}$ & $\mathbf{\%} \mathbf{2 0 0 8 - 2 0 0 7}$ \\
\hline Argentina & 4.822 .014 & 3.576 .276 & 5.702 .385 & 3.155 .174 & $10,64 \%$ & $-44,67 \%$ \\
\hline Brasil & 3.522 .901 & 6.401 .728 & 8.411 .201 & 7.175 .350 & $32,30 \%$ & $-14,69 \%$ \\
\hline Paraguay & - & - & - & - & - & - \\
\hline Perú & 227.064 & 113.147 & 160.131 & 127.604 & $0,14 \%$ & $-20,31 \%$ \\
\hline Colombia & 71.799 & 141.709 & 14.798 & 68.565 & $0,11 \%$ & $363,35 \%$ \\
\hline Uruguay & 62.594 & 257.213 & 42.263 & 39.029 & $0,41 \%$ & $-7,65 \%$ \\
\hline
\end{tabular}

Fuente: Elaboración propia a partir de EFA (2009).

9. De hecho, recomiendo encarecidamente el estudio que acomete este autor sobre la evolución de la AOD en la región latinoamericana entre 1988 y 2002, estructurándola en tres etapas en función de los intereses recaídos sobre la primera: hasta 1989, donde destaca el I Plan de Cooperación Integral con Centroamérica, de 1990 a 1994, con la preponderancia de los créditos FAD (Fondo de Ayuda al Desarrollo) y de 1995-2002 con la orientación definitiva de la Ayuda hacia los Objetivos Del Milenio (ODM).

10. Puesto que aquí quizá sea bueno recordar de nuevo, aunque contextualizándolo ahora sobre la región: "es sabido que la cooperación española bilateral tiene un sesgo particular hacia América Latina, pero el aumento relativo de la cooperación hacia África Subsahariana explica esta leve corrección en los destinatarios de la AOD española" (Intermón Oxfam, 2008, p. 35). 
Remitiéndonos directamente, en efecto, a los países que van a ser ya objeto de atención en el siguiente apartado, cabe reconocer cómo el país sobre el que comenzó invirtiéndose más fue Argentina, seguido de Brasil, aunque en las cifras correspondientes a 2008 el foco de interés se centra en Brasil muy por encima de Argentina. Destacan igualmente las fluctuaciones, aunque con un monto financiero mucho menor, de las que son objeto países como Colombia, cuyo saldo es netamente positivo, o Perú, cuyo interés ha ido en franco declive. En líneas generales, tan sólo uno de los países, Colombia, puede salir fortalecido por la AOD bilateral invertida en educación.

¿Cómo se estructura el vector educativo por parte de la AOD bilateral? El cuadro que a continuación se expone refleja los apartados que se han considerado a efectos de organizar y gestionar la ayuda, incluyendo los códigos correspondientes de adjudicación:

\section{Cuadro 1. Distribución por sectores CAD/CRS de la AOD bilateral bruta} en educación

\begin{tabular}{|c|c|c|c|c|}
\hline $\begin{array}{l}\text { CÓD. } \\
\text { CAD }\end{array}$ & $\begin{array}{l}\text { CÓD. } \\
\text { CRS }\end{array}$ & $\begin{array}{l}\text { TÍTULO } \\
\text { SECTOR }\end{array}$ & DESCRIPCIÓN SECTOR & $\begin{array}{c}\text { ACLARACIONES/ } \\
\text { INFORMACIÓN ADICIONAL }\end{array}$ \\
\hline $\begin{array}{l}1 \\
1 \\
1\end{array}$ & $\begin{array}{l}11110 \\
11120 \\
11130 \\
11181\end{array}$ & $\begin{array}{l}\text { Educación, } \\
\text { nivel no } \\
\text { especificado }\end{array}$ & $\begin{array}{l}\text { - Política educativa y gestión } \\
\text { administrativa. } \\
\text { - Servicios e instalaciones } \\
\text { educativas y formación. } \\
\text { - Formación de profesores. } \\
\text { - Investigación educativa. }\end{array}$ & $\begin{array}{l}\text { Se aplicarán los códigos de esta } \\
\text { categoría únicamente cuando se } \\
\text { desconozca o no se especifique el } \\
\text { nivel educativo correspondiente a un } \\
\text { determinado proyecto (por ejemplo: } \\
\text { para la formación de profesores de } \\
\text { enseñanza primaria corresponderá el } \\
\text { código 11220). }\end{array}$ \\
\hline $\begin{array}{l}1 \\
1 \\
2\end{array}$ & $\begin{array}{l}11220 \\
11230 \\
11240\end{array}$ & $\begin{array}{l}\text { Educación } \\
\text { Básica }\end{array}$ & $\begin{array}{l}\text { - Educación Primaria. } \\
\text { - Capacitación básica para } \\
\text { los jóvenes y adultos. } \\
\text { - Educación de primera } \\
\text { infancia. }\end{array}$ & $\begin{array}{l}\text { Enseñanza primaria infantil académica } \\
\text { y no académica; toda enseñanza } \\
\text { básica y de primer ciclo sistemática; } \\
\text { suministro de material escolar. } \\
\text { Enseñanza académica y no académica } \\
\text { para capacitación básica de jóvenes y } \\
\text { adultos (educación de adultos); } \\
\text { alfabetización y aprendizaje de cálculo } \\
\text { aritmético elemental. } \\
\text { Educación preescolar académica y no } \\
\text { académica. }\end{array}$ \\
\hline $\begin{array}{l}1 \\
1 \\
3\end{array}$ & $\begin{array}{l}11320 \\
11330\end{array}$ & $\begin{array}{l}\text { Educación } \\
\text { Secundaria }\end{array}$ & $\begin{array}{l}\text { - Educación Secundaria. } \\
\text { - Formación Profesional. }\end{array}$ & $\begin{array}{l}\text { Enseñanza sistemática de segundo ciclo } \\
\text { en todos sus niveles (jóvenes y adultos). } \\
\text { Formación profesional básica y } \\
\text { enseñanza técnica a nivel secundario; } \\
\text { formación en el puesto de trabajo; } \\
\text { formación de aprendices; se incluye } \\
\text { formación profesional no académica. }\end{array}$ \\
\hline $\begin{array}{l}1 \\
1 \\
4\end{array}$ & $\begin{array}{l}11420 \\
11430\end{array}$ & $\begin{array}{l}\text { Educación } \\
\text { Post- } \\
\text { secundaria }\end{array}$ & $\begin{array}{l}\text { - Educación universitaria. } \\
\text { - Formación superior técnica } \\
\text { y de dirección. }\end{array}$ & $\begin{array}{l}\text { Licenciaturas y Diplomaturas } \\
\text { universitarias, de enseñanza superior, } \\
\text { de escuelas politécnicas; becas. } \\
\text { Programas de formación profesional } \\
\text { para trabajadores y formación de } \\
\text { empleados. }\end{array}$ \\
\hline
\end{tabular}


Cifras como las expuestas líneas arriba, así como todas sus especificaciones, han constituido el objeto de atención y análisis atento por parte de diferentes ONGD y expertos en esta temática (Mesa, 1995; CONGDE, 2004; Entreculturas, Alboan y Etea, 2005 y 2008, Ortega et al., 2006) y no se sustraen al efecto de las críticas emitidas desde las mismas, justificadas desde su carácter profesional y su compromiso militante con las poblaciones del Sur. De sus respectivos análisis, en efecto, cabe considerar que, con carácter general, el sector educativo constituye uno de los principales receptores de fondos de la AOD española bilateral, como lo muestran los análisis realizados. Pero de los estudios se extrae también que existe un avance involutivo, dado que en el año 2000 éstos se multiplicaron por más de dos; en 2001-2002 se mantuvieron en el mismo nivel y en 2003-2004 disminuyeron considerablemente. Esta tendencia a la baja no se corresponde con la tendencia generalizada, ascendente, de la AOD bilateral total.

En cuanto a su distribución geográfica se reconoce cómo, en los años evaluados (2000-2006), el 35\% de la AOD en educación se concentra en Marruecos, Colombia, Perú, Venezuela, Bolivia, Ecuador y Guinea Ecuatorial. Llama la atención, además, la naturaleza del binomio 'origen de las contribuciones bilaterales a educación' y 'nivel de sistema educativo que prioriza' en los países en desarrollo: el Ministerio de Asuntos Exteriores (que gestionaba la AOD antes que el MAEC) destinó más de la mitad de su flujo a educación post-secundaria; las Comunidades Autónomas, principalmente la vasca, valenciana, navarra y catalana no priorizaron tampoco a la educación básica; las entidades locales centraron su interés en la inversión en infraestructura escolar y el Ministerio de Educación aportó buena parte de sus fondos al subsector 'Servicios e instalaciones educativos', para mantener los colegios españoles en el exterior. Son, finalmente, las ONGD las que destinaron el $25 \%$ de sus fondos a la educación básica, frente a 22\% de educación secundaria, sólo un 3,3\% a educación postsecundaria y el resto a 'educación en un nivel no especificado'. En cuanto a la distribución de ámbitos de la AOD en educación, en el periodo 20002006 , cabe reconocer que la mayor parte de los fondos (66\%) se concentraron en los sectores 'Educación nivel no especificado' y 'Educación secundaria'.

Resulta llamativo, finalmente, que la AOD española reembolsable para educación (dentro de FAD-Fondo de Ayuda al Desarrollo ${ }^{11}$ ) supuso el 18\% de la misma. Ante esta realidad, puede reconocerse, tal y como sostienen Ortega et al. (2004) que "estamos ante un instrumento de importancia cuantitativa considerable en la AOD

11. Los créditos FAD constituyen el instrumento crediticio a través del cual España ofrece a los gobiernos, instituciones o empresas de países en desarrollo condiciones de financiación que se vinculan a la adquisición de bienes españoles, lo que supone el $75 \%$ de la ayuda oficial al desarrollo de tipo bilateral, y que ponen de manifiesto que la racionalidad de la Ayuda española es básicamente comercial. Como indican Gómez (1994) y Mesa (1995), entre la promoción de productos españoles que se ha realizado con los créditos FAD se encuentra, incluso, la venta de armas a países que han sido acusados de violar los derechos humanos, como en Indonesia o China. Por su parte, el Ministerio de Asuntos Exteriores señala que la concesión de créditos FAD seguirá orientándose "hacia la financiación de proyectos de infraestructura y desarrollo de la base productiva" (MAEC, 2009a, p. 31). 
española pero, sin embargo, dudamos de su orientación hacia la educación como sector estratégico para la lucha contra la pobreza" (p. 197).

\section{RADIOGRAFÍA SOCIOEDUCATIVA A LAS UNIDADES DE COMPARACIÓN: DEMANDAS Y FUERZAS DESDE LA EDUCACIÓN}

De acuerdo con lo apuntado en la introducción, a continuación se expondrán una serie de datos acerca de las unidades de comparación escogidas, extraídas del último informe EPT (2009), a fin de tener más elementos de juicio a la hora de demandar una AOD en educación eficaz y sensible al desarrollo humano, que permita, según el último informe del PNUD (2010) incidir en la vida de las personas en aspectos como "influir en la capacidad de la gente para elegir sus líderes, en las decisiones públicas y en compartir conocimientos" (p. 20). Para ello se revisarán los datos que a continuación se presentan, aglutinados en tablas que comienzan por dar una visión del contexto socioeconómico y aterrizan en lo específicamente educativo.

Tabla 2. Datos demográficos y relativos al SIDA

\begin{tabular}{|l|c|c|c|c|c|c|c|c|}
\hline & $\begin{array}{c}\text { TOTAL } \\
\text { POBLACIÓN } \\
\mathbf{( 0 0 0 )} \\
(\mathbf{2 0 0 6})\end{array}$ & $\begin{array}{c}\text { TASA MEDIA } \\
\text { ANUAL } \\
\text { CRECIMIENTO } \\
\mathbf{0 - 4} \text { AÑOS }\end{array}$ & $\begin{array}{c}\text { ESPERANZA } \\
\text { DE VIDA AL } \\
\text { NACER } \\
(\mathbf{2 0 0 5 - 2 0 1 0 )})\end{array}$ & $\begin{array}{c}\text { TASA DE } \\
\text { FERTILIDAD } \\
\text { TOTAL (HIJOS } \\
\text { POR MUJER) } \\
(\mathbf{2 0 0 5 - 2 0 1 0 )}\end{array}$ & $\begin{array}{c}\text { TASA DE } \\
\text { MORTALIDAD } \\
\text { INFANTIL } \\
(\mathbf{2 0 0 5 - 2 0 1 0 )}\end{array}$ & $\begin{array}{c}\text { BEBÉS CON } \\
\text { BAJO PESO } \\
\text { AL NACER } \\
(\mathbf{1 9 9 9 - 2 0 0 6 )})\end{array}$ & $\begin{array}{c}\text { TASA DE } \\
\text { PREVALECEN- } \\
\text { CIA DE SIDA } \\
\text { EN ADULTOS } \\
(\mathbf{1 5 - 4 9 )}\end{array}$ & $\begin{array}{c}\text { \% DE } \\
\text { MUJERES } \\
\text { VIVIENDO } \\
\text { CON SIDA } \\
(\mathbf{2 0 0 7 )}\end{array}$ \\
\hline Argentina & 39.134 & 0.6 & 75 & 2.3 & 13 & 7 & 0.5 & 27 \\
\hline Brasil & 189.323 & 0.0 & 72 & 2.2 & 24 & 8 & 0.6 & 34 \\
\hline Paraguay & 6.016 & 0.3 & 72 & 3.1 & 32 & 9 & 0.6 & 29 \\
\hline Perú & 27.589 & 0.2 & 71 & 2.5 & 21 & 11 & 0.5 & 28 \\
\hline Colombia & 45.558 & -1.0 & 73 & 2.2 & 19 & 9 & 0.6 & 22 \\
\hline Uruguay & 3.331 & -0.8 & 76 & 2.1 & 13 & 8 & 0.6 & 28 \\
\hline
\end{tabular}

Fuente: elaboración propia a partir de EFA (2009).

De los datos seleccionados merece la pena destacar la enorme distancia poblacional que separa, por ejemplo, a Uruguay, el país menos poblado, de Brasil (no en vano, se ha dicho que Brasil es ya, en sí misma, una región debido a la heterogeneidad de sus provincias y a la extensión vasta de su territorio). La tasa anual de crecimiento es negativa para dos países (Colombia y Uruguay). La mayor esperanza de vida la presenta Uruguay y la menor, Perú, aunque en todos los países ronda los setenta años. También se halla cierta uniformidad en el número de hijos, dado que la mujer tiene una media de dos hijos (a excepción de Paraguay, con 3,2). Preocupa más la tasa de mortalidad infantil, dado que es de 32 precisamente para el país que he nombrado en último lugar, Paraguay (32), seguida de Brasil (24) y Perú (21). Con independencia de estos datos, todos los países presentan cifras sensiblemente 
altas. En íntima relación con este dato, Perú detenta un índice elevado de infancia recién nacida con bajo peso (11), seguidos por Paraguay y Colombia (9). Finalmente, con respecto al SIDA, Ilama la atención las altas tasas de prevalencia en adultos, basculando entre 0,3 y 0,6 en todos los países y cómo el SIDA azota a las mujeres en Brasil (34\%) y en Perú y Uruguay (34\% y 28\%, respectivamente).

Tabla 3. PIB, ayudas, pobreza y desigualdad

\begin{tabular}{|c|c|c|c|c|c|c|}
\hline & \multicolumn{2}{|c|}{ PIB DÓLARES } & \multirow{2}{*}{$\begin{array}{c}\text { POBLACIÓN CON } \\
\text { MENOS DE } 1 \text { \$ AL DÍA } \\
(1990-2005)\end{array}$} & \multirow{2}{*}{\begin{tabular}{|c|} 
POBLACIÓN CON \\
MENOS DE $2 \$$ AL DÍA \\
$(1990-2005)$
\end{tabular}} & \multirow{2}{*}{$\begin{array}{l}\text { INDICE DE GINI } \\
(1992-2005)\end{array}$} & \multirow{2}{*}{$\begin{array}{c}\text { AYUDA NETA PER } \\
\text { CAPITA (EN DÓLARES) } \\
(\mathbf{2 0 0 5 )}\end{array}$} \\
\hline & 1998 & 2006 & & & & \\
\hline Argentina & 8020 & 5120 & 7 & 17 & 51 & 3 \\
\hline Brasil & 4880 & 4710 & 8 & 21 & 57 & 1 \\
\hline Paraguay & 1650 & 1410 & 14 & 30 & 58 & 14 \\
\hline Perú & 2440 & 2980 & 11 & 31 & 52 & 14 \\
\hline Colombia & 1650 & 3120 & 7 & 18 & 59 & 11 \\
\hline Uruguay & 3360 & 6070 & 19 & 40 & 48 & 2 \\
\hline
\end{tabular}

Fuente: elaboración propia a partir de EFA (2009).

EI PIB ha aumentado en Perú, Colombia y Uruguay (en estos dos últimos países, el doble) mientras que ha disminuido en Argentina, de modo flagrante, seguido por Brasil y Uruguay, éstos de forma más leve. Los datos arrojados por la población que vive con menos de un dólar al día es ciertamente bajo, pero el porcentaje asciende significativamente cuando la medida es la de dos dólares en Uruguay (40), Paraguay (30) y Brasil (21). Finalmente, cabe Ilamar la atención sobre el Coeficiente de Gini, mostrando una desigualdad patente entre los que más y menos tienen del total de la población: Colombia con 59 y Paraguay con 58 ejemplifican muy bien esta distancia medida por el mismo.

El EDI (Índice de Desarrollo Educativo) ${ }^{12}$ constituye una herramienta heurística muy valiosa desde el momento que calibra y equilibra los vectores que pueden

12. Oxfam Internacional ha realizado un esfuerzo por medir algunos aspectos de las diferencias educativas entre países en desarrollo, con el objetivo de identificar aquellos factores que más influyen en el rendimiento educativo nacional. Para ello, ha elaborado una herramienta de medición denominada 'Índice de Desarrollo Educativo' (IDE o EDI en inglés), que clasifica a los países en función de su rendimiento en tres áreas: matriculación en la escuela, terminación de estudios y equidad entre sexos. El IDE calcula la diferencia media que separa a un país del resultado ideal (100\% de matriculación y terminación y 0\% en diferencia entre sexos), lo que significa que los países con un IDE más bajo son aquellos que presentan unos mejores resultados. Se ha establecido una "línea de privación extrema", por debajo de la cual se sitúan los países que tienen un déficit superior al 33\% (más de un tercio de los niños fuera del colegio, menos de esa proporción lo terminan y la diferencia entre niños y niñas es también superior al 33\%). 
legitimar la constitución de una política educativa de calidad, exigencia y equidad, dado que, como no podía ser de otra forma, permanece fiel al principio de la trascendencia de poseer una educación básica a lo largo y ancho de la vida. Para medir y comparar el EDI de los países objeto de estudio me he permitido añadir, por un lado, los resultados de los dos primeros países en el ranking (Kazajistán y Japón) y, por otro, los resultados de España, aun reconociendo que puede ser humana y éticamente reprobable hacerlo así: mi intención no es otra que la que persigue en parte todo análisis comparado, la de comprobar las distancias existentes respecto a un indicador cuyo criterio se ha establecido homogéneamente para todos los países.

Tabla 4. EDI (Índice de Desarrollo Educativo)

\begin{tabular}{|l|c|c|c|c|c|c|}
\hline & EDI & No EDI $^{\circ}$ & $\begin{array}{c}\text { TASA ALUMNADO } \\
\text { EN EDUCACIÓN } \\
\text { PRIMARIA (\%) }\end{array}$ & $\begin{array}{c}\text { TASA DE } \\
\text { ALFABETIZACIÓN } \\
\text { DE ADULTOS }\end{array}$ & $\begin{array}{c}\text { ÍNDICE ESPECífICO } \\
\text { DE GÉNERO (IEG) }\end{array}$ & $\begin{array}{c}\text { TASA DE } \\
\text { SUPERVIVENCIA } \\
\text { HASTA 5 }{ }^{\circ} \text { GRADO }\end{array}$ \\
\hline Argentina & 0.956 & 51 & 0.991 & 0.976 & 0.961 & 0.897 \\
\hline Brasil & 0.901 & 80 & 0.901 & 0.956 & 0.896 & 0.817 \\
\hline Paraguay & 0.935 & 68 & 0.949 & 0.936 & 0.977 & 0,877 \\
\hline Perú & 0.931 & 70 & 0.990 & 0.887 & 0.951 & 0.895 \\
\hline Colombia & 0.905 & 79 & 0.920 & 0.923 & 0.962 & 0.817 \\
\hline Uruguay & 0.963 & 47 & 1.000 & 0.978 & 0.943 & 0.931 \\
\hline Kazajistán & 0.995 & 1 & 0.990 & 0.996 & 0.993 & 1.000 \\
\hline Japón & 0.994 & 2 & 0.998 & 0.992 & 0.998 & 0.990 \\
\hline España & 0.985 & 18 & 0.997 & 0.974 & 0.969 & 1.000 \\
\hline
\end{tabular}

Fuente: elaboración propia a partir de EFA (2009).

De acuerdo con estas premisas, cabe estar atento a los puestos que ocupan países como Uruguay (47) y Argentina (51), seguidos a distancia por el resto, con un Brasil a la cola, ocupando un puesto 80. La tasa de alumnado de educación primaria es muy alta, siendo de nuevo Brasil el más bajo $(0,90)$ y el más alto Uruguay con un 1. La tasa de alfabetización de adultos nos invita a estar atentos, puesto que Perú muestra un 0,88, aunque el resto de los países supere el $90 \%$. Finalmente, la tasa de supervivencia en el quinto año de escolarización es la que más ha de llamarnos la atención, dado que es baja en Colombia $(0,81)$ y en Brasil $(0,87)$, seguidos por Paraguay, Argentina y Perú con 0,89: el alumnado permanece en las aulas los primeros años de escolarización, pero el "cuello de botella" se inicia ya a esta temprana edad educativa. Los datos de la última tabla que a continuación se ofrece ayudan a ratificar y complementar esta realidad: 
Tabla 5. Infancia fuera de la escuela, tasas de egreso y repetición

\begin{tabular}{|l|c|c|c|c|c|c|c|c|c|c|}
\hline & \multicolumn{4}{|c|}{$\begin{array}{c}\text { INFANCIA FUERA DE LA ESCUELA } \\
(\mathbf{0 0 0})\end{array}$} & \multicolumn{3}{c|}{$\begin{array}{c}\text { REPETIDORES DE TODOS LOS } \\
\text { GRADOS (\%) }\end{array}$} & \multicolumn{3}{|c|}{$\begin{array}{c}\text { TASAS DE EGRESO EN ENSEÑANZA } \\
\text { PRIMARIA (\%) 2 }{ }^{\circ} \text { GRADO }\end{array}$} \\
\cline { 2 - 12 } & $\mathbf{1 9 9 9}$ & $\begin{array}{c}\% \\
\text { Mujeres }\end{array}$ & $\mathbf{2 0 0 6}$ & $\begin{array}{c}\% \\
\text { Mujeres }\end{array}$ & Total & Hombres & Mujeres & Total & Hombres & Mujeres \\
\hline Argentina & 10 & 52 & 36 & 86 & 6.4 & 7.6 & 5.2 & 1.9 & 2.2 & 1.6 \\
\hline Brasil & 1033 & $\ldots$ & 597 & 36 & 18.7 & $\ldots$ & $\ldots$ & 2 & $\ldots$ & $\ldots$ \\
\hline Paraguay & 28 & 46 & 43 & 46 & 5.1 & 6.1 & 4.1 & 1.7 & 2.1 & 1.2 \\
\hline Perú & 6 & 100 & 33 & 9 & 8.7 & 9.0 & 8.4 & 2.5 & 2.3 & 2.7 \\
\hline Colombia & 369 & 46 & 367 & 48 & 3.8 & 4.4 & 3.3 & 3.4 & 4.4 & 2.3 \\
\hline Uruguay & $\ldots$ & $\ldots$ & $\ldots$ & $\ldots$ & 5.4 & 6.5 & 4.2 & 0.4 & 0.5 & 0.3 \\
\hline
\end{tabular}

Fuente: Elaboración propia a partir de EFA (2008).

Esta última tabla, en efecto, reproduce buena parte de datos ante los que deberemos mostrar cierta atención, dado que apunta a la vulneración clara de uno de los derechos más significativos de la infancia: los niños y niñas que egresan antes de la escolaridad obligatoria y el volumen de infancia que se halla hoy fuera de la escuela. Desde este punto de vista, en lo correspondiente a este último indicador, cabe destacar la evolución positiva detectada en países como Brasil (de 1.033.000, cifra altísima, en 1999, se pasa a 597.000 en 2006, lo que, aun así, sigue resultando significativamente alto). Lo mismo ocurre con Colombia: disminuye en dos unidades, pero nos quedamos con la poca honrosa cifra de que 367.000 niños y niñas en edad escolar no disfrutan de este derecho. El resto muestra, sin embargo, una evolución negativa en el transcurso de los años evaluados: de 10.000 a 36.000 en Argentina, de 28.000 a 43.000 en Paraguay y de 6.000 a 33.000 en Perú. La tasa de repetidores es alta, siendo la mayor en Brasil $(18,7)$ y la menor en Colombia $(3,8)$. Por sexos, siempre el índice se muestra más proclive hacia las mujeres. Finalmente, el alumnado que egresa de los sistemas educativos antes de finalizar es muy alto en Colombia $(3,4)$ y muy bajo en Uruguay $(0,5)$. Si nos atenemos a la variable 'sexo', excepto en Perú, sucumben ante los estudios antes los hombres que las mujeres.

Como conclusiones a esta amplia pero reveladora mirada educativa de los países objeto de estudio, hemos asistido, a través de las cifras comparativas, a algunos de los aspectos educativos que se muestran, dentro del amplio sentido de la 'educación básica' defendida desde UNESCO, susceptibles de mejora, como lo han mostrado ser, de manera notable en algunos países, la tasa de mortalidad infantil, la desigualdad de oportunidades económicas de la población medida desde el índice de Gini, las tasas de alfabetización adulta, la tasa de supervivencia en el 5ํㅜ curso, la evolución positiva de infancia fuera de la escuela o las tasas altas de repetidores y egresados. Ante esta realidad, ¿cómo reacciona nuestra AOD en estos países?

13. Ni en tercero ni en cuarto existían, en los países escogidos, datos para comparar. 


\section{Algunas Reflexiones a LA LUZ DE LAS PRIORIDADES DE LA AOD EN EDUCACIÓN: ENTRE LO DESEABLE Y LO POSIBLE}

Para ir concluyendo, y dado el espacio que obliga este formato de difusión, recurriré a un documento concreto: el anexo III del Plan Director de Cooperación Española más reciente, referido al año 2009, que recoge las acciones en función de 'áreas preferentes por país'14:

Cuadro 2. Acciones en educación del PACI 2009 en las áreas preferentes por país

\begin{tabular}{|c|c|c|c|c|}
\hline PAÍS & GRUPO & $\begin{array}{l}\text { CÓD. } \\
\text { CAD }\end{array}$ & \begin{tabular}{|c|} 
CÓD. \\
CRS
\end{tabular} & DESCRIPCIÓN \\
\hline Argentina & $\mathrm{C}$ & 111 & 11110 & $\begin{array}{l}\text { Política educativa y gestión administrativa. Política sector educativo, } \\
\text { programación y planificación; ayuda a ministerios de educación, } \\
\text { administración y sistemas de gestión; asesoramiento y fortalecimiento } \\
\text { institucional; desarrollo planes de estudio y materiales; actividades } \\
\text { educativas sin especificar. }\end{array}$ \\
\hline \multirow[t]{2}{*}{ Brasil } & C & 111 & 11110 & $\begin{array}{l}\text { Educación, nivel no especificado. Se aplicarán los códigos de esta } \\
\text { categoría únicamente cuando se desconozca o no se especifique } \\
\text { el nivel educativo. }\end{array}$ \\
\hline & & 113 & 11330 & $\begin{array}{l}\text { Formación profesional. Formación profesional básica y enseñanza } \\
\text { técnica a nivel secundario; formación en el puesto de trabajo; } \\
\text { formación de aprendices; se incluye formación profesional no } \\
\text { académica. }\end{array}$ \\
\hline \multirow[t]{2}{*}{ Paraguay } & A & 111 & 11110 & $\begin{array}{l}\text { Política educativa y gestión administrativa. Política sector educativo, } \\
\text { programación y planificación; ayuda a ministerios de educación, } \\
\text { administración y sistemas de gestión; asesoramiento y fortalecimiento } \\
\text { institucional; desarrollo planes de estudio y materiales; actividades } \\
\text { educativas sin especificar. }\end{array}$ \\
\hline & & 112 & 11230 & $\begin{array}{l}\text { Capacitación básica de jóvenes y adultos. Enseñanza académica y no } \\
\text { académica para capacitación básica de jóvenes y adultos (educación } \\
\text { de adultos); alfabetización y aprendizaje de cálculo aritmético } \\
\text { elemental. }\end{array}$ \\
\hline Perú & A & 111 & 11110 & $\begin{array}{l}\text { Política educativa y gestión administrativa. Política sector educativo, } \\
\text { programación y planificación; ayuda a ministerios de educación, } \\
\text { administración y sistemas de gestión; asesoramiento y fortalecimiento } \\
\text { institucional; desarrollo planes de estudio y materiales; actividades } \\
\text { educativas sin especificar. }\end{array}$ \\
\hline
\end{tabular}

14. Otros dos recursos que podrían utilizarse y que arrojarían más luz a este análisis, cuyo fin no es otro que detectar cuáles son las líneas directrices de trabajo en la política de cooperación española al desarrollo en educación, serían, por un lado, recurrir al documento 'De la Relación de ayudas y subvenciones de cooperación Internacional concedidas en el segundo trimestre del año 2009', emitido por la Agencia Española de Cooperación Internacional para el Desarrollo, en el que se exponen las operadas en educación por sectores geográficos o, ésta mucho más exhaustiva, recurrir directamente a revisar, una por una, todas las acciones planificadas dentro del $\mathrm{PACl}$, seleccionando de todas ellas las educativas y las de los países objeto de estudio. La última versión disponible de las tablas en la web nos remiten al PACI 2008 que reconoce por su parte 14.324 acciones de cooperación española bilateral (1.976.928.540 euros) y 11.468 de multilateral (1.431.805.913 euros). 


\begin{tabular}{|c|c|c|c|c|}
\hline PAÍS & GRUPO & $\begin{array}{l}\text { CÓD. } \\
\text { CAD }\end{array}$ & $\begin{array}{c}\text { CÓD. } \\
\text { CRS }\end{array}$ & DESCRIPCIÓN \\
\hline \multirow[t]{2}{*}{ Perú } & & 112 & 11230 & $\begin{array}{l}\text { Capacitación básica de jóvenes y adultos. Enseñanza académica y no } \\
\text { académica para capacitación básica de jóvenes y adultos (educación } \\
\text { de adultos); alfabetización y aprendizaje de cálculo aritmético } \\
\text { elemental. }\end{array}$ \\
\hline & & 113 & 11330 & $\begin{array}{l}\text { Formación profesional. Formación profesional básica y enseñanza } \\
\text { técnica a nivel secundario; formación en el puesto de trabajo; } \\
\text { formación de aprendices; se incluye formación profesional no } \\
\text { académica. }\end{array}$ \\
\hline Colombia & B & 151 & 15162 & $\begin{array}{l}\text { Derechos humanos. Supervisión del respeto de los derechos humanos; } \\
\text { apoyo a organizaciones nacionales y regionales de derechos humanos; } \\
\text { protección de las minorías étnicas, religiosas y culturales [actividades } \\
\text { no relacionadas con operaciones consolidación paz (15061). }\end{array}$ \\
\hline \multirow[t]{2}{*}{ Uruguay } & $\mathrm{C}$ & 312 & 31281 & Educación, formación forestal \\
\hline & & 410 & 41081 & Educación / formación medioambiental \\
\hline
\end{tabular}

Fuente: Elaboración propia a partir de PACI (2009).

Dedicaré un comentario a cada uno de los países, en base a sus demandas iniciales, especialmente centradas en el concepto de 'educación básica' al que he aludido desde el principio, y cuáles son las opciones prioritarias de la política española:

- Argentina: si bien es cierto que se erige en uno de los países más desarrollados económicamente de esta selección, cabe recordar que su PIB ha disminuido ostensiblemente. Su EDI es alto, pero ocupa un puesto 51 y la tasa de supervivencia en quinto curso es de un 0,89. Aun así, la AOD española se centra en 'política educativa' como prioridad para trabajar en la región.

- Brasil. Constituye el país más desigual: su tasa de mortalidad infantil es significativa, así como sus tasas de SIDA, especialmente femenino. Su PIB ha disminuido y las personas que viven con 2 dólares al día alcanza el índice de 21. Ya en educación, el EDI ocupa el puesto 80. Su tasa de alumnado en primaria es la más baja de los países estudiados $(0,90)$ y la tasa de supervivencia en quinto curso vuelve a ocupar el último puesto de las 6 unidades de comparación. A pesar de haber tenido una evolución apabullante de disminución de cifras de infancia fuera de la escuela, sigue mostrando números muy altos. La cooperación española prioriza 'educación a nivel no especificado' y 'formación profesional'.

- Colombia: a pesar de que Colombia tiene cifras importantes de deserción escolar, así como de egreso y de número de repetidores en las clases, la cooperación española entiende que no han de existir prioridades en materia educativa. No me he resistido, sin embargo, a apuntar en el cuadro una prioridad marcada, en relación con los Derechos Humanos, cuya vinculación con la educación es siempre directa.

- Paraguay: país no muy bien situado en las cifras manejadas (a la tasa anual de crecimiento económico negativa para el año estudiado, se suma el hecho de 
que la infancia fuera de la escuela haya sido altamente negativa: de 28.000 a 43.000), la cooperación educativa trabaja en directrices de 'gestión política' y en 'capacitación básica', que incluiría la alfabetización de adultos.

- Perú: Éste es el país en el que se detectan más deficiencias socioeducativas en primera infancia: tasas altas de mortalidad infantil, de personas con SIDA y de supervivencia en el alumnado de quinto grado $(0,89)$, entre otros. Muestra cifras significativamente bajas de alfabetización de adultos: 0,88. Quizá por ello la cooperación española entiende que la 'capacitación de adultos', conjuntamente con la 'política educativa' y la 'Formación Profesional' constituyen las preferencias en este año. Es el país que mayor número de prioridades muestra.

- Uruguay: aunque se reconozca que el nivel socioeducativo de este país sitúa al mismo en una posición desahogada respecto al resto... ¿Ello ha de ser óbice para que la única referencia a prioridades educativas que haya encontrado se refieran a las señaladas en el gráfico, establecidas además, y obviamente, desde otros sectores?

Ateniéndonos, así, a esta interpretación, concluyo con una serie de reflexiones que vuelven sobre el discurso inicial de la AOD y se dirigen hacia una serie de recomendaciones sobre las que ésta debería incidir en materia educativa, en especial con respecto a la 'educación básica', que ha sido aquí señalizada a través del EDI:

En primer lugar, de acuerdo con Sánchez (2008), sigue teniendo un peso excesivo la ayuda bilateral española sobre la región latinoamericana (según el CAD, en el 2002 casi el $40 \%$ frente al $11 \%$ de otros países CAD), ayuda cuyo peso de estos préstamos está ligada a las adquisiciones de bienes en España por parte del país receptor. Lo anterior condiciona enormemente la AOD sobre la región y cada uno de sus sectores, al tiempo que nos permite reflexionar sobre que es necesario un mayor esfuerzo por parte de los responsables de la cooperación española para aumentar la participación de las donaciones en la composición de la ayuda bilateral española a América latina y así reducir el peso de la ayuda ligada con el fin de mejorar tanto la valoración distributiva como la calidad de la ayuda (p. 124). El fortalecimiento, en el sector educativo, de la ayuda multilateral gestionada desde organismos internacionales como UNESCO condicionaría en buena medida la consecución de una educación de calidad y equidad de mayor alcance. A lo anterior se une la, ya muchas veces demostrada, naturaleza impredecible de la AOD: Intermón Oxfam (2008) denuncia que tan sólo el 46\% de las asignaciones que los donantes comprometen se hacen efectivas en el año correspondiente en las cuentas de los países receptores. Esta falta de predictibilidad limita seriamente su contribución a una estrategia de reducción de la pobreza, lo que está afectando de modo más que notable a nuestro objeto de estudio, la educación.

En segundo lugar, del análisis global que diversos autores e instituciones hacen de la evaluación de la AOD en el sector de la educación, se extrae la conclusión de que la cuantía de la cooperación internacional española que dedica a la educación en general y a la educación básica, que aquí hemos querido plasmar con las cifras del segundo apartado, está muy por debajo del nivel marcado por las recomendaciones adoptadas en diversos foros y cumbres internacionales y cristalizadas en los ODM. Por todo ello, y este estudio así lo corrobora, bajo la premisa de que, en efec- 
to, un mayor nivel de conciencia social y política de la prioridad de la educación en las estrategias de desarrollo resulta más que perentorio, en este tema las fuentes consultadas recomiendan una alineación con los compromisos internacionales y una priorización de una educación básica de calidad para todos en función de las necesidades regionales, pero también de las estrategias nacionales internas. La CONGDE arroja una cifra concreta en esta línea, basándose en estudios prospectivos: el 70\% de la AOD debiera dedicarse a educación básica y educación secundaria (CONGDE, 2006).

Para ir concluyendo, y en tercer lugar, en este artículo se ha atendido a los datos leídos e interpretados desde el EDI (Índice de Desarrollo Educativo) procedente del último informe EPT de UNESCO (2009). Aun reconociendo que las cifras han de erigirse en medios, y no en fines, para la actuación eficaz en política educativa ${ }^{15}$, éstas muestran, respecto a los seis países estudiados, que debe de aumentarse la cobertura de educación infantil y mejorar la calidad de la educación primaria para que no se extienda la tendencia a la repetición y, por ende, a la deserción escolar, tal y como indicaban las cifras, todavía poco honrosas, de 'infancia fuera de la escuela', presentadas. Por ello, y si finalmente volvemos sobre la hipótesis y refrendando el título de este artículo, en efecto se corrobora cómo la AOD en materia educativa no es excesivamente sensible a los requerimientos y demandas socioeducativas que se hacen desde las categorías de comparación escogidas, al priorizar en estos países aspectos como la gobernabilidad en política educativa y la formación profesional. Este carácter, en definitiva, las alinea a las directrices en política educativa difundidas y priorizadas por organismos como el Banco Mundial o el DAC (Comisión de Ayuda al Desarrollo de la OCDE), lo que se identificaría con mera 'ayuda', parafraseando al título, siendo ésta considerada como un requisito formalista y de naturaleza obligatoria por parte de los países desde el compromiso adoptado la ONU en 1972, frente a la casi perenne necesidad de contar con una cobertura completa de educación preprimaria y primaria, al tiempo que consolidar la alfabetización y capacitación de adultos, que definiría, a mi juicio, una auténtica 'cooperación al desarrollo' : un compromiso veraz y horizontal entre países con miras a un auténtico desarrollo humano, social y sostenible que atienda a "su naturaleza sustentable, equitativa, empoderadora (sic) y su inherente flexibilidad" (PNUD, 2010: 3). Como trasfondo, no actuar bajo estos parámetros está suponiendo el no cumplimiento e incluso violación de uno de los derechos intrínsecos e inherentes de la infancia: la educación.

\section{REFERENCIAS BIBLIOGRÁFICAS}

Agencia Española de Cooperación Internacional (1998). Ley de Cooperación Internacional para el Desarrollo y Disposiciones reglamentarias. Madrid: AECI-Vicesecretaría General.

15. Dado que conviene resaltar que, en la actualidad, la justicia de los derechos sociales como la educación, reclaman de nuevos cauces para garantizar su cumplimiento. Entre ellos, cada vez adquieren más importancia los indicadores que señalan los progresos en la implementación de las políticas públicas, entre otras, las educativas. 
Agencia Española de Cooperación Internacional (2002). Información general. Madrid: AECI-Vicesecretaría General.

Agencia Española de Cooperación Internacional y Desarrollo (s.d.). Relación de ayudas y subvenciones de cooperación Internacional concedidas en el segundo trimestre del año 2009. Madrid: Agencia Española de Cooperación Internacional para el Desarrollo.

ALONSO, J. A. (1999). Estrategia para la cooperación española. Madrid: Ministerio de Asuntos Exteriores.

CONGDE (2004). Ayuda y educación: un reto para la cooperación española. Madrid: Coordinadora de ONG para el Desarrollo de España.

CONGDE (2006). AOD hoy. Discurso y realidad. Madrid: CONGDE-Fundación Santa María.

DCD/DAC (99)20 - 20 JULIO 1999. Clasificación de la Ayuda según el sector de destino del país receptor. Madrid: MAEC.

Educación para Todos-EPT (2009). Superar la desigualdad. Por qué es importante la gobernanza. Informe Global EPT. Paris: UNESCO.

Entreculturas, Alboan y Fundación Etea para el Desarrollo y la Cooperación (2005) La AOD en educación a examen: un análisis de la cooperación española en 1999-2004. Madrid: Entreculturas-Alboan-Fundación Etea.

Entreculturas, Alboan y Fundación Etea para el Desarrollo y la Cooperación (2008). AOD en educación a examen. Análisis de la Cooperación Española 2005-2006. Madrid: Entreculturas-Alboan-Fundación Etea.

GÓMEZ, C. (1994). España y la Ayuda Oficial al Desarrollo. Los créditos FAD. Informe SIP/CIP 9. Centro de Investigación para la Paz/Seminario Permanente de Investigación para la Paz. Madrid y Zaragoza.

INTERMON-OXFAM (2009). La realidad de la Ayuda 2008-2009. Una evaluación independiente de la ayuda al desarrollo española e internacional. Madrid: Intermon Oxfam.

JORDÁN, J. y ANTUÑANO, I. (2001). Las relaciones Sur-Norte. Una mirada valenciana. Valencia: Patronat Nord-Sud, Servei de Publicacions de la Universitat de València.

MESA, M. (1995). Otras formas de cooperar: presión política y educación. Papeles, 55 Zaragoza. Centro de Investigaciones para la Paz (CIP). Fundación Hogar del Empleado.

Ministerio de Asuntos Exteriores y de Cooperación (2009). Borrador del Seguimiento del PACI 2008. Madrid: Ministerio de Asuntos Exteriores y de Cooperación, Secretaría de Estado de Cooperación Internacional y Dirección General de Planificación y Evaluación de Políticas para el Desarrollo.

Ministerio de Asuntos Exteriores y de Cooperación (2009a). Plan Anual de Cooperación Internacional. Madrid: Ministerio de Asuntos Exteriores y de Cooperación, Secretaría de Estado de Cooperación Internacional y Dirección General de Planificación y Evaluación de Políticas para el Desarrollo.

Ministerio de Asuntos Exteriores y de Cooperación (2010). Plan Anual de Cooperación Internacional. Madrid: Ministerio de Asuntos Exteriores y de Cooperación, 
Secretaría de Estado de Cooperación Internacional y Dirección General de Planificación y Evaluación de Políticas para el Desarrollo.

Ministerio de Asuntos Exteriores-AECI (2009). Programa de Cooperación Interuniversitaria e Investigación Científica. Áreas prioritarias por País (Plan Director de la Cooperación Española). Madrid: MAEC.

ORTEGA, M. L., HERNÁNDEZ, A. y TORRES, M. (2006). La Ayuda Oficial al Desarrollo bilateral española en educación en el periodo 1999-2004: perfil y recomendaciones. Revista de Fomento Social, 61, 185-212.

PNUD (2010). La verdadera riqueza de las naciones: caminos al desarrollo humano. Edición del Vigésimo aniversario. Nueva York: PNUD.

SÁNCHEZ, E. J. (2008). La nueva agenda internacional del desarrollo y la distribución de la ayuda española a América Latina (1987-2002). En A. Montes Del Castillo y M.J. Martínez (Coords.), Migraciones, cultura y desarrollo (pp. 109-125). Murcia: Servicio de Publicaciones de la Universidad de Murcia y Agencia Española de Cooperación Internacional.

VÉLAZ DE MEDRANO, C. (2005). Los retos de la educación básica en América Latina. Prioridades para la Ayuda Oficial al Desarrollo. Madrid: Siglo XXI/CeALCIFundación Carolina. 